\title{
The research on the countermeasures of the breakthrough of bottleneck and the healthy development of the city tennis
}

\author{
Qie Xiaoying \\ Xijing University, Xi'an, 710123, China
}

Keywords: city tennis, present situation, influence factor, development countermeasures

\begin{abstract}
Tennis once called the noble sport, has gone gradually into the city national fitness activities. In this paper we analyzed and researched the prominent problems in its development and put forward countermeasures, in order to provide reference for the development of city tennis. The tennis movement situation in the city is carried out. We researched the influence of the sites and the facilities to the city tennis and discussed the exercise ways, the psychological characteristics and the level of consumption of the tennis lovers to further promote the development of the city tennis and its market. This topic will research on to the development status quo and the problems of city tennis, in order to break through the difficulties in city tennis development and promote the virtuous development of the city of tennis.
\end{abstract}

\section{Introduction}

With the improvement of people's living standards, the tennis sport is popularized rapidly in our country, deeply popular in all age groups. As a regional city, in order to promote the national fitness, the municipal government, part of the enterprises and institutions, and sports fitness club build some tennis court in order to meet the people's needs of playing tennis, and in the community construction planning tennis venue as district of basic facilities shall be considered by some real estate developers. Tennis once referred to as the "noble sport" has gradually went into urban people's fitness activities. But compared to Beijing, Shanghai, Guangzhou and other cities, tennis are still relatively backward in the development of the city.

\section{The significance city tennis}

Known as "the second ball," the tennis is interesting, ornamental and athletics at an organic whole, with its regulatory, ornamental and recreational it has become one of the most favorite sports of people. Has a significant effect in improving people's health, adjusting psychology, improving the comprehensive ability of people.

Tennis movement has great significance to improve the city people's physical condition.

Tennis movement is a high level of competitive projects, unlike regular sports, tennis sport has a significant role in adjusting psychology, enhancing physical fitness and purifying the mind. Tennis is a kind of beneficial aerobic exercise, can consume the body fat of athletes just right and with the greatest degree. At the same time, because the range of tennis movement is larger, the activity sites of the athletes is comprehensive, almost all their muscle tissue of the body is able to balance and get sufficient exercise. Playing tennis athletes need attention in the process of highly concentrated, accurately judge the direction of the ball, through the tennis training can enhance the athletes' thinking ability and response capabilities, improve their balance and master the ability of time. Often taking part in the tennis, can make the tennis sports people be more confident and more optimistic in daily life. Playing tennis has no special requirements on age. It is able for all the people with free movement to attend in this activity. Research has shown that from children aged 4 to 90 years old man can take part in the sport, but for different ages, different physical condition play according to their own practice and improve the speed and rhythm, as long as this activity is based on the play under condition of body, it will not affect any basic enjoy in playing, it is also one of the reasons why world millions of people love the sport. Tennis, as it were, truly realize the aim that entertainment psychological, emotional and physical exercise. 


\section{Tennis can improve people's comprehensive ability}

Society is more and more fierce competition, only to set up a powerful competitive consciousness, can be in impregnable fierce competition in the future. And tennis can rapidly develop people's ability to compete, for example, the ability to observe things, the ability to analyze things, fast strain capacity and the ability of self-control, and other aspects. The premise of tennis is not afraid of hard, daring to bear hardships, the tennis sports can cultivate people's brave fighting spirit.

\section{Survey results and analysis of the present situation of tennis}

Tennis belongs to high consumption sports projects, the ministry of education has stipulated that "around to carry out the sports should conform to the local economic development level, and combined with the school's own superiority, choose the students' loving sports ", this sentence is also suitable for urban sports development. Urban has the economic base for the development of tennis. According to the city reports by related department, with the constant improvement of the local economic development level, major changes have taken place in the local residents' consumption structure, the Engel's coefficient decreased significantly, far below the national average level, this laid a solid foundation for the development of tennis sport and popularize. The spread of tennis sport is established on the basis of certain economy, its development must be adapted to the economic development level. City sports funds is large and sports facilities is relatively perfect, although the tennis place is not sound enough, however, the local solid economic foundation provides a strong protection for the development of tennis sport.

\section{Tennis sports venue resources situation}

"The handy woman cannot do meal without rice ", the resources of the tennis court how good or bad, directly determines the development level and scale of tennis, any tennis birth has a direct relationship with its "hardware" facilities. Overall, the city tennis court is in short supply, is far from meeting the needs of people on the tennis court.

\section{Motivation of people involved in tennis sport}

Survey shows that the motivations people take part in the tennis sport showed a trend of diversification, most people want to participate in sport for physical and mental health, as health sports concept is deeply rooted in the hearts of the people at the same time, people give a higher assessment of tennis in such aspects as psychology, social function. The purpose people want to participate in the tennis sport, in addition to the physical fitness, edify sentiment, also is that they want to reflect their own pursuit of social progress and civilization through this fashion, elegant movement. This reflects the more and more people's vibrant, positive mindset, and a better understanding of the new poetry, it could also be one of the reasons for people's interest in tennis.

\section{The investigation and analysis of teachers}

Tennis sport has quite high requirement to the coaches, coaches must received professional training in order to better shoulder to raise the level of city tennis, the important task of training a good tennis player, authors give a analysis of city university and the university tennis teachers (coaches) qualification and professional skill of the investigation, detailed investigation and analysis results are shown in the table below:

Table. 1 urban tennis teachers (coaches) educational background questionnaire $(\mathrm{N}=$ ?)

\begin{tabular}{|c|c|c|c|c|}
\hline Education & $\begin{array}{l}\text { Graduate } \\
\text { student }\end{array}$ & Undergraduate & Junior College & Other \\
\hline $\mathrm{N}$ & 4 & 8 & 6 & 2 \\
\hline$\%$ & $20 \%$ & $40 \%$ & $30 \%$ & $10 \%$ \\
\hline
\end{tabular}


Table.2 tennis teachers (coaches) tennis professional skills training questionnaire $(\mathrm{N}=$ ?)

\begin{tabular}{|c|c|c|c|}
\hline index & $\begin{array}{l}\text { Professional } \\
\text { training }\end{array}$ & $\begin{array}{l}\text { Without } \\
\text { professional } \\
\text { training }\end{array}$ & Other \\
\hline $\mathrm{N}$ & 8 & 10 & 2 \\
\hline$\%$ & $40 \%$ & $50 \%$ & $10 \%$ \\
\hline
\end{tabular}

From table 1 and table 2 investigation results we can see that in a survey of city tennis coaches, there are four teachers having graduate student degree, the bachelor degree is most and there are 8 people, accounted for $40 \%$ of investigation number. At the same time, in the 20 surveyed teachers, only eight people touched by the professional tennis training, and other 12 people have not trained professional and systematic professional tennis, accounted for $60 \%$ of investigation number. It seems that $60 \%$ of the city's tennis teachers (coaches) had no system of tennis sport specific training, however, $60 \%$ of the teachers (coaches) have a bachelor's degree, both received special sports training system, have a good base for quality, have a good sports skills, therefore, the skill ability to accept sports is stronger. In addition, I also found in the survey, in the 50 physical education teachers, the vast majority are young teachers, this part of the teachers' ability is stronger in accepting new things. So on the whole, the city's tennis teachers (coaches) teachers is good, have the basic requirement of tennis teaching.

\section{Investigation and analysis of the population situation participated in the tennis}

Most of industries in the city don't know or don't to participate in this sport. And in the crowd of playing tennis, most are the teachers, the government civil servants, leadership and staff of banks and large enterprise that the sports consumption capacity is higher and have certain levels of knowledge and the leisure time. Through interviews, the above crowd has a strong interest in tennis, some people spend almost more than two hours of time to play tennis every day, to explain their enthusiasm for the sport. Some of the city leaders are also very interested in this sport, look it as a major means of fitness. This is the favorable conditions of tennis sport in the city development.

\section{The development countermeasures of city tennis sport}

According to the investigation and analysis of the above, I according to the specific condition of city urban area put forward the following countermeasures.

\section{To strengthen the construction of tennis court, improvement in tennis field}

Funds investment is limited, less space, construction speed is slow, that is common problem around tennis development, also is the important factor restricting for the development of tennis sport. Tennis court directly affect the quality and quantity of the tennis sport activity way and organizational form of the lack of tennis court, unable to meet the needs of people taking part in the tennis sports, seriously affected the learning enthusiasm of people, restrict the development of tennis sport, become the "bottleneck" of sport development. Wanting the tennis to be a higher level development, we must continue to deepen reform, strengthen the construction of tennis court, increase the financial input in tennis sport resources, increase the number of site, improve site condition.

Take the lead in the development of tennis sport pulled by the government

Wanting the promotion and popularization of tennis in medium-sized city, the guiding role of the government is indispensable. To be led by the government, the tennis sports development must can do bigger contribution for the economic development of the government. Tennis is successful people's favorite sports activities in developed parts, to develop the tennis project might have a different approach, set up investment promotion and capital introduction of high-speed channel. In addition, a city must have the characteristics of culture and sports, the current urban per capita in the living standards has gradually improved, per capita income is growing too, and the climate is 
suitable for tennis.

\section{Establish a tennis folk organization, and promote the tennis event}

In addition to the departments advocate of government, we also should to encourage tennis enthusiasts organization association or a similar organization to develop the tennis sport. The city government leadership organize tennis association, and every year do the organization of large tennis match, reflected good by society, it is a good start.

\section{Tennis combined with education, set up tennis lessons at school}

Tennis sport in our country is in a stage of vigorous development, and the first introduction and wide tennis is in the national colleges and universities, the national college tennis match has held 10 times, more than 100 colleges and universities participated in the game.

Host and participate various levels of sports to promote communication, improve the level of tennis training and competition

The one charm of sports lies in the games, the game process is full of adventure, the result of the game can stimulate hard work training. And through training, people can communicate, think how to hit the ball, play better, improve the flexibility and psychology to bear ability, the brain directly promote the level of tennis training and to increase the competitive level.

\section{References}

[1] Wang Xinghua. Analysis and Prospect of the development of urban leisure tennis sport [J]. Neijiang science and technology, 2010, (4): 144-145.

[2] Xue Zhenwu, Li He. Feasibility study on the development of the enlightenment tennis in primary and secondary schools [J]. Neijiang science and technology, 2008, :11-12.

[3] Cai Kezhang. Research and Analysis on the status quo of amateur tennis in Yichang [J]. sports education research, 2011, .186-187.

[4] Zhang Jing. Research on the development prospect of The Racquet Club Hotel in Xi'an [J]. Inner Mongolia sports science and technology, 2009,22 (1):17-20.

[5] Dai ting. Research on the present situation of tennis development in Wuhan [J]. Hubei sports science and technology, 2011,30 (1): -117. (in Chinese)

[6] Liu Xinxin. Analysis of the effect of tennis practice wall on tennis technique [J]. Neijiang science and technology, 2011, .161.

[7] Wang Mingming, On the sustainable development of tennis in China [P]. China: 610068.

[8] Zhang Yanze. Feasibility analysis of tennis in primary and secondary schools in Kunshan [D]. Suzhou: Soochow University, 2010.

[9] Huang Jianjun.Study on the present situation and sustainable development of tennis in Jiangmen [N]. Journal of Wuyi University, 2010-2 (24). 